\title{
Morphology quiz: Identification of metastatic cells in pleural effusion
} Summary "Inside this month's Cytopathology »

Quiz related to cytological examination of pleural effusion in a patient with history of laterothoracic malignant melanoma

\section{Case history}

- 46-year-old man.

- Diagnosed with a melanoma on the right lateral thoracic wall (SSM, Clarck level IV, Breslow thickness $1.72 \mathrm{~mm}$ ).

- Treated with local surgery and resection of sentinel lymph nodes.

- Presenting with a pleural effusion, 19 months after initial diagnosis, which was collected and sent for cytology.

See images page 5.

\section{Question 1}

Based on the images provided on the following page (Figure 1), the pleural effusion contains:
A. macrophages
B. numerous lymphocytes
C. mainly neutrophils
D. dyskaryotic cells suspicious of malignancy

\section{Question 2}

What component(s) can be identified with the Fontana Masson stain (Figure 1 D)?
A. Argentaffin granules
B. Melanin
C. Iron
D. Lipids

\section{Question 3}

What is your interpretation of the immunocytochemical staining on Figure 2?
A. Reactive mesothelial cells
B. Metastatic non small cell carcinoma
C. Metastatic carcinoid tumor
D. Metastatic malignant melanoma 


\section{Question 4}

Concerning the etiology (primary tumour) of malignant pleural effusions, classify the following malignancies in order of frequency:
A. Breast cancer
B. Malignant melanoma
C. Lung cancer
D. Non-Hodgkin's lymphoma

\section{Question 5}

Which mutation(s) should be tested in the case of malignant melanoma for therapeutic management?
A. KRAS mutation
B. EGFR mutation
C. BRAF V600E mutation
D. ALK rearrangement

\section{Answers on page 3}

\section{Recommended Reading}

1. Ordóñez NG .Value of melanocytic-associated immunohistochemical markers in the diagnosis of malignant melanoma: a review and update. Review article. Hum Pathol. 2014 Feb;45(2):191-205. doi: 10.1016/j.humpath.2013.02.007

2. Porcel JM, Etiology of pleural effusions: analysis of more than 3,000 consecutive thoracenteses. Arch Bronconeumol. 2014 May; 50(5):161-5. doi: 10.1016/j.arbres. 2013.11.007.

Diane FRANKEL ${ }^{1,2 *}$, Andrée ROBAGLIA-SCHLUPP ${ }^{1}$, Donatienne BOURLARD ${ }^{1}$, Elise KASPI $^{1,2}$ and Patrice ROLL ${ }^{1,2}$

1 APHM, Hôpital la Timone, Service de Biologie Cellulaire, Marseille, France

2 Aix Marseille Univ, INSERM, MMG, Marseille, France

* Corresponding author:

Dr Diane Frankel, PharmD. Aix-Marseille Univ, INSERM, MMG -

Aix Marseille University, Faculty of Medicine la Timone, 27, Boulevard Jean Moulin, 13385, Marseille, France, E-mail: diane.frankel@univ-amu.fr, Phone: +33 491324 934, Fax number: +33 491384676 


\section{Figure 1.}

Cytology of pleural effusion: Papanicolaou stain, x40 (panels A, B); May-Grünwald-Giemsa stain, x40 (Panel C); Fontana-Masson stain, x40 (Panel D). Scale bar: 10 $\mu \mathrm{m}$

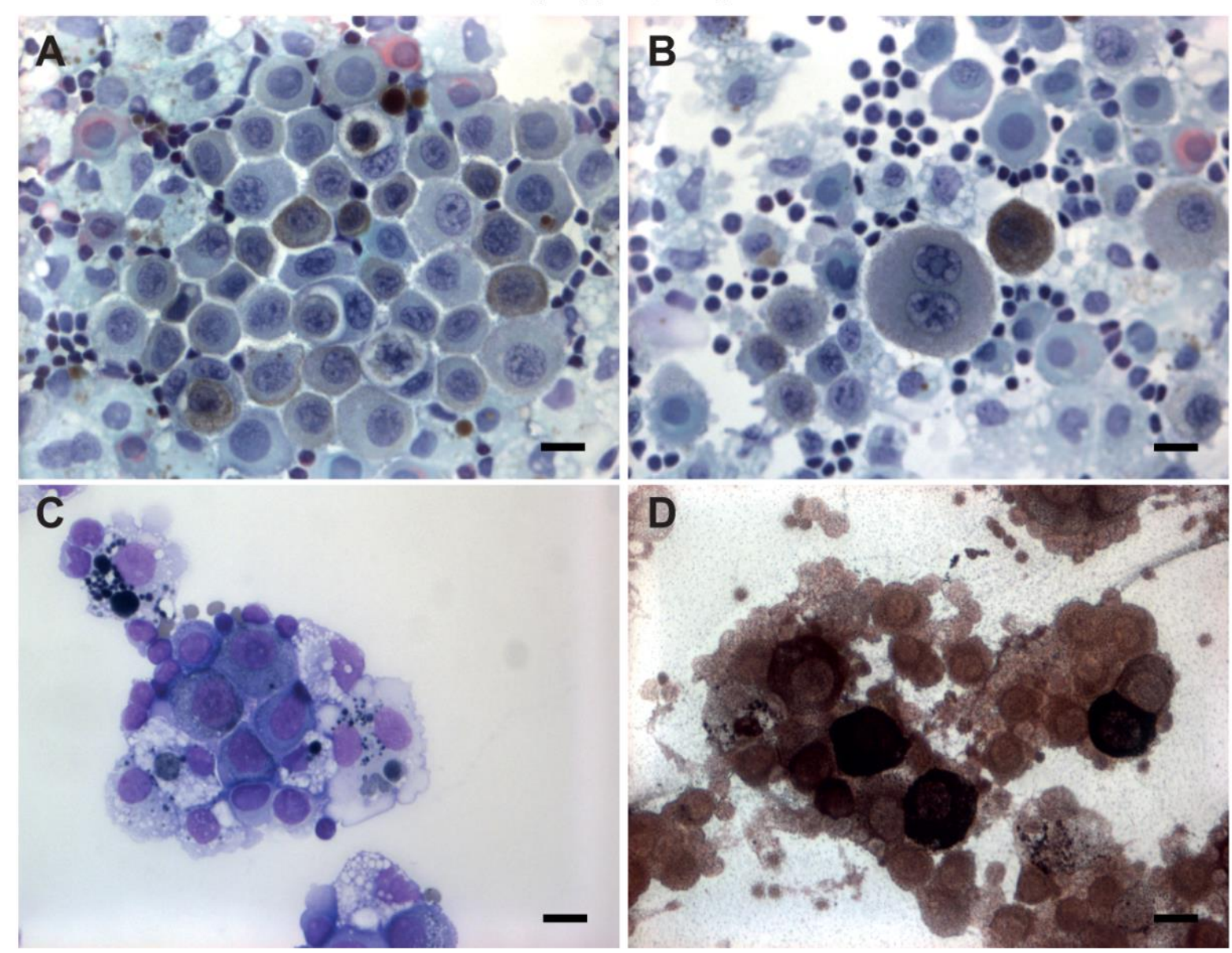




\section{Figure 2.}

Immunocytochemistry (peroxidase staining, $\mathrm{x} 40$ ) using antibodies against cytokeratins (clones AE1/AE3/PCK26), vimentin (clone V9), EpCAM (clone MOC31), S-100 protein (rabbit polyclonal), HMB45 (clone HMB45) and melan A (clone A103). Mouse IgG and polyclonal rabbit IgG were used as isotypic controls. Scale bar: $10 \mu \mathrm{m}$

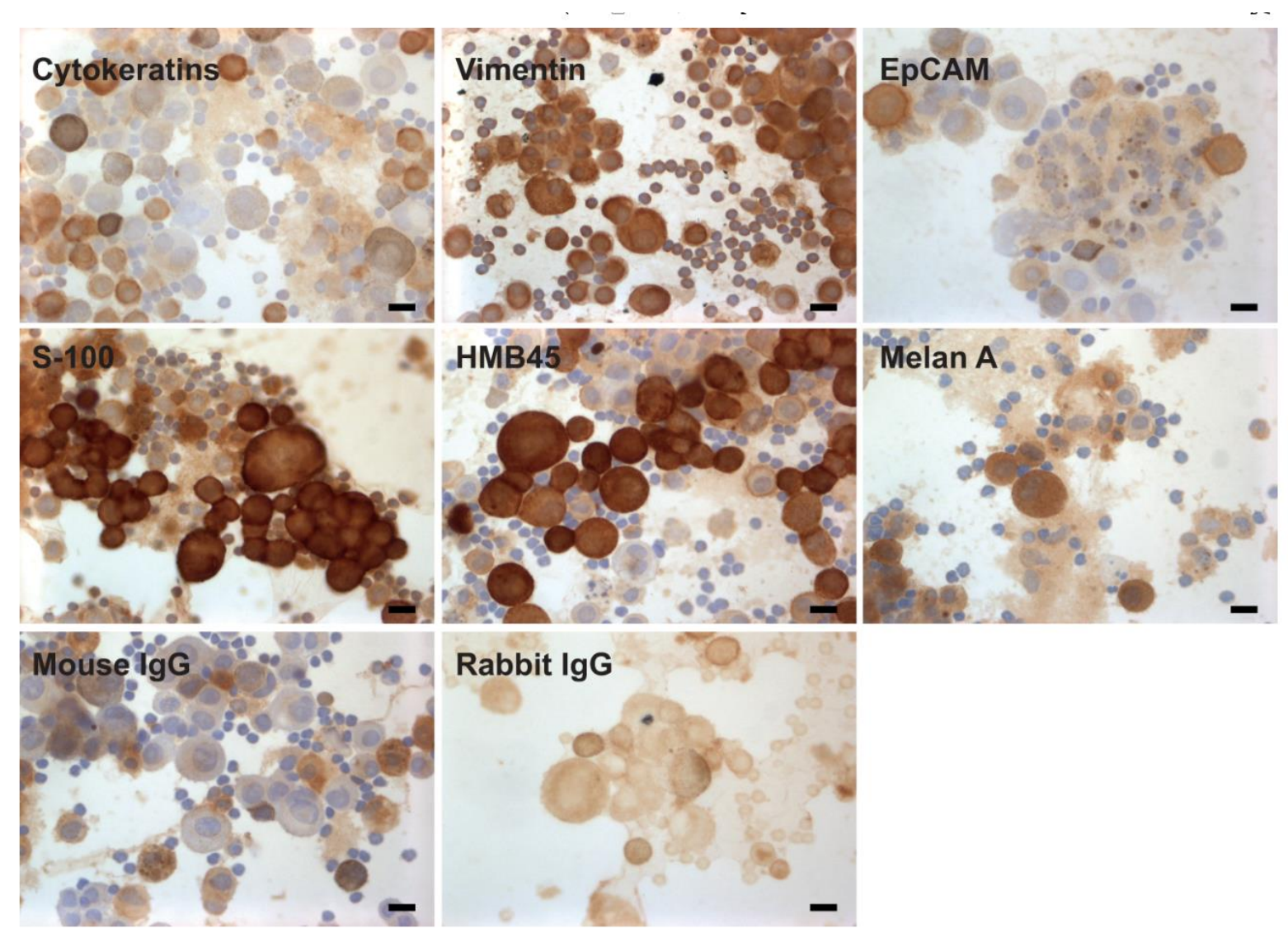




\title{
Answers to Morphology Quiz: Page 1
}

\section{Question 1}

\author{
Answer: A, B and D.
}

Question 2

\section{Answer: A and B.}

Comments: Fontana stain will stain melanin, lipofuschins, and argentaffin granules which are observed in carcinoid tumors.

\section{Question 3}

\section{Answer: A and D.}

Comments: malignant cells show cytoplasmic staining with vimentin, S-100 protein, HMB45 and melan A antibodies, whereas no staining was observed with antibodies against cytokeratins and EpCAM. Reactive mesothelial cells are negative with melanoma markers and show a cytoplasmic staining with cytokeratin, vimentin and EpCAM antibodies.

\section{Question 4}

\section{Answer: $\mathbf{C}>\mathrm{A}>\mathrm{D}>\mathrm{B}$.}

Comments: in a study of 840 malignant pleural effusions, lung cancer represented $37 \%$ of cases with $18 \%$ for lung adenocarcinoma, breast cancer $16 \%$, non-Hodgkin's lymphoma $7 \%$ and melanoma $0,01 \%$ (Porcel et al.)

\section{Question 5}

\section{Answer: C.}

Comments: For the patient, the V600E mutation in BRAF was positive on sentinel node at diagnosis. The mutation was detected for a second time at the relapse in the $11 \mathrm{R}$ mediastinal node. In France, BRAF V600E is found in $34.7 \%$ of malignant melanoma (www.e-cancer.fr). This mutation is not specific for malignant melanoma and can also be found in other malignant tumours such as lung cancer (2\% of cases) or Hairy cell leukemia (79 to $97 \%$ of cases) for example. 